\title{
Prey Density and Diet of Snow Leopard (Uncia Uncia) In Shey Phoksundo National Park, Nepal
}

\author{
Bishnu Prasad Devkota ${ }^{1, *}$, Thakur Silwal ${ }^{1}$, Jaromir Kolejka ${ }^{2}$ \\ ${ }^{1}$ Tribhuvan University, Institute of Forestry, Pokhara, Nepal \\ ${ }^{2}$ Associate Professor, Masaryk University, Czech Republic \\ *Corresponding author: devkotabishnu@yahoo.com
}

Received June 5, 2013; Revised June 27, 2013; Accepted July 10, 2013

\begin{abstract}
The food habit of the snow leopard (Uncia uncia) is not always according to the availability of its prey species. The aim of the study was to estimate wild prey densities in Shey-Phoksundo National Park in relation to diet composition. In addition, the study sought to determine livestock depredation status and its frequency of occurrence in the diet of snow leopards. Population density of blue sheep (Pseudois nayaur) was estimated by vantage point count methods. Densities of other wild prey species were estimated through line transect methods and analyzed via the DISTANCE 6.0 program. Household surveys $(\mathrm{n}=250)$ were conducted to determine livestock numbers and frequency of depredation. Scats $(\mathrm{n}=40)$ were analyzed through micro histolysis to determine the diet composition of snow leopards. Himalayan marmots (Marmota himalayana) had the highest density (132.6 animals/ km2), while blue sheep had a density of 2.3 animals/ km2. Most local inhabitants were subsistence farmers, many dependent upon local livestock breeds, with an average holding of 32.6 animals/ household. There was a loss of 3.6 animals/ household annually, with a total depredation rate of $11.1 \%$. Annual loss to snow leopards averaged 1.6 animals/ household and this was the major source of mortality. Blue sheep was the major prey item, with a $30 \%$ occurrence in the snow leopard diet. Among the livestock, sheep was the major prey item with a $15 \%$ frequency of occurrence in the scat. Food habits of snow leopard were independent of the density of its prey species; there was no proportional relationship between the prey density and the diet of snow leopards.
\end{abstract}

Keywords: diet, livestock depredation, predator, prey density, scat analysis

Cite This Article: Devkota, Bishnu Prasad, Thakur Silwal and Jaromir Kolejka, "Prey Density and Diet of Snow Leopard (Uncia Uncia) In Shey Phoksundo National Park, Nepal.” Applied Ecology and Environmental Sciences, 1, no. 4 (2013): 55-60. doi: 10.12691/aees-1-4-4.

\section{Introduction}

The snow leopard (Uncia uncia) is the top predator of the high altitude mountains of central and southern Asia and is the striking symbol of world's highest place [20]. Its population is declining throughout its range due to various survival threats including habitat and prey loss and persecution [15]. Knowledge of prey density and predatorprey ratios can help set limits for validating snow leopard numbers in a particular area. There must be sufficient prey to support the predicted predator population [8]. The snow leopard is an opportunistic predator capable of killing prey more than three times its own weight. Therefore, it may potentially prey on most herbivores found in the same range except for fully grown yak or wild ass [20]. In general, food habit studies indicate that the primary prey of the snow leopard consists of the dominant wild ungulates of the region, along with a variety of smaller birds and mammals [8].

Loss of livestock to wild predators is an important cause of anxiety amongst Himalayan pastoralists [10]. Livestock depredation has become a significant problem across the snow leopard range in central Asia, being most severe in and around protected areas [21]. Theoretically, snow leopards should attack livestock as their secondary prey only when their natural prey is either depleted or hard to find. Therefore, its dependency on domestic livestock increases conflicts with the local communities and has resulted in increased retaliatory killing. This has been an important issue in snow leopard conservation throughout its range. Snow leopards have been reported to kill livestock in most parts of their range but the extent of this predation and its impact on local herders is poorly understood [13].

Diets of small and large carnivores have been evaluated by identifying prey species from hair in scats (Windberg and Mitchell 1990: cited in Maheshwari 2006 [12]). The analysis of scats has become a fundamental tool in carnivore research [14]. Scat analysis has the great advantage that material is easy to collect and does not involve destruction of animals from the study population. An understanding of the snow leopard's diet is important in order to elucidate other aspects of its ecology and to design and implement conservation programs [18]. Snow leopards are reported to kill domestic livestock over most of their range $[6,13,20,22]$, which brings them into conflict with humans, but the extent of this predation has not been thoroughly assessed. Analysis of snow leopard 
scat can show whether and to what extent, livestock are represented in the diet [18].

Most information available on the diet of snow leopard is based on the analysis of scat only, without prior knowledge of prey density of the area under study. In this study, we have analysized the diet relating it to the density of wild prey species and livestock populations, giving insight into snow leopard prey preference. This study will further advance our understanding of snow leopard ecology by linking scat analysis to domestic and wild prey distribution and abundance across the landscape. The understanding gained from this study aims to aid in management and conservation of upland protected areas.

\section{Materials and Methods}

\subsection{Study Area}

Shey Phoksundo National Park (29॰15’-2945’ N and

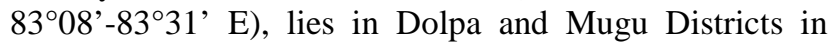
Mid-Western Development Region of Nepal, whose micro-climatic condition, ecology, ecosystem and flora and fauna resemble the Tibetan desert type. The study was carried out in three Village Development Committees (VDCs) of Shey Phoksundo National Park namely, Phoksundo, Bhijer and Saldang (Figure 1). Saldang and Bhijer represent the Trans-Himalayan bio-climate zone, whereas, Phoksundo represent South Himalayan and Inner- Himalayan zone [5].

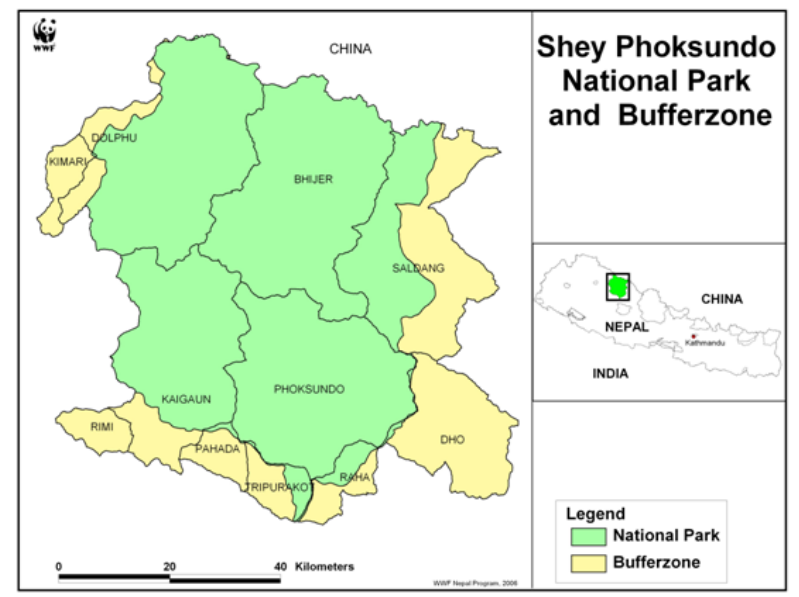

Figure 1. Map of the Study Area (WWF Nepal 2006)

Located within the rain shadow of Mt. Dhaulagiri (8172 $\mathrm{m})$, the park experiences sharp seasonal differences in temperature and rainfall. The annual precipitation ranges from $500 \mathrm{~mm}$ in the northern steppes to $1500 \mathrm{~mm}$ in the South [5]. Vegetation is highly diversified due to altitudinal variations and intrinsic climatic variations. In the south, the steep hill slopes are dominated by temperate and sub-alpine vegetation. In the lower valley, dense forests are composed of blue pine (Pinus wallichiana) intermixed with spruce (Picea smithiana), deodar (Cedrus deodara), hemlock (Tsuga dumosa), and silver fir (Abies spectabilis). Silver birch (Betula utilis), and juniper (Juniperus recurva) dominate the landscape at the upper tree line [5].

The park is home to more than 32 species of mammals, 200 species of birds, 6 species of reptiles and 28 species of butterfly [3]. The park supports several endangered species of wild animals, which also include; snow leopards (Uncia uncia), wolves (Canis lupus), and musk deer (Moschus chrysogaster).

\subsection{Wild Prey Species Densities}

For the survey of wild prey species, 27 lines-transects ranging from $0.7 \mathrm{~km}$ to $1.4 \mathrm{~km}$ (mean $1.1 \mathrm{~km}$ ) was laid with a total length of $28.6 \mathrm{~km}$. All the species were directly observed from transect, the distance of the animal from transect was measured using Range finder and the angle taken using a pocket compass [7]. When an animal group was first encountered, bearings were taken. Although the animals usually flush from their original location as approached, the bearings were recorded, as nearly as possible, to the original location of the animals, not the location at the time of subsequent bearings [7]. From the transect, animal groups were scanned using $8 \times 30$ binoculars and 15-60x zoom spotting scope to identify the prey species and their number. For blue sheep, a total area of $134.1 \mathrm{~km} 2$ was surveyed around Shey, Sambling and Bhijer blocks and direct observations in the morning (0600-1000 hrs) and evening (1400-1700 hrs) from the transects/ trails and fixed point method (vantage point) was conducted $[8,16,20]$. The transect data were analyzed using the program DISTANCE 6.0 [26] to estimate species density.

\subsection{Livestock Status and Depredation}

A well designed questionnaire with close ended questions was prepared and interpreted in Nepali language for ease of enumerators. Enumerators, proficient both in Nepali and Tibetan language were trained to fill the questionnaire. Total households $(n=250)$ in different settlements of the village were considered for the household survey following the method used by Sharma et al. (2006) [23]. Depredation of one year period was only considered for the study. Data were analyzed using Microsoft excel 2007.

\subsection{Scat Analysis}

\subsubsection{Field Method}

Scats $(n=40)$ were collected along a fixed trail $[8,11]$ in 27 transects which covered the length of $28.6 \mathrm{~km}$; transect length $0.7-1.4 \mathrm{~km}$. To ensure that samples are authentically from snow leopards, they were collected adjacent to snow leopard signs such as scrapes and scent sprays or claw rakes. Furthermore, the presence of felid hair in scats is commonly used to assess the identity of cat species [11]. The scats were identified on the basis of size and associated signs such as scrapes and pugmarks.

\subsubsection{Laboratory Method}

Standard micro-histological methods were used to identify prey through the scats hair. In the laboratory, the remains of prey species were separated and dried. To identify hair remains, hair samples were collected from domestic livestock, live wildlife and stuffed specimens in museum collections. These were used to prepare original slides for identification following the methods outlined by Teerink (1991) [24] and Oli et al. (1993) [18]. 
Scats were washed with tap water in a fine mesh sieve and indigestible remains of hair, teeth, hooves, bones, feathers were air dried for 48 hours. The hair was cleaned thoroughly in diethyl ether for 10 minutes and dried between blotting paper and preserved in polyethylene bags [17]. Twenty hairs samples were randomly selected from each sample to prepare the slide and determine multiple prey species [14]. Slides were prepared for each sample extracted from snow leopard scat in the laboratory using 100x magnification microscope and photomicrographs taken. Gelatin solution was used to prepare slides to see cuticular structure (Figure 2) of the hair and the cuticular scales were observed by the impression techniques. Prey species were identified by comparison with a reference collection of slides and photographs of the structure of hair of potential prey species [24].

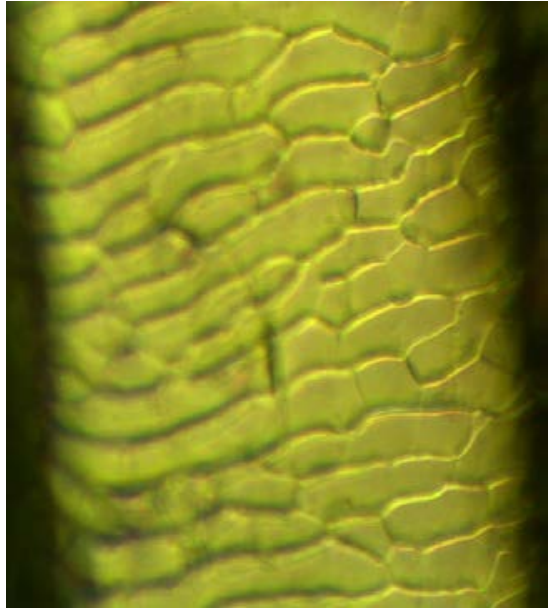

Figure 2. Cuticle structure of Pseudois nayaur

Table 1. Density and density of cluster of six prey species of snow leopard

\begin{tabular}{|c|c|c|c|c|c|c|}
\hline \multirow{2}{*}{ Prey Species } & \multicolumn{2}{|c|}{ Density } & \multicolumn{3}{c|}{ Density of Cluster } \\
\cline { 2 - 7 } & D & SE & $95 \%$ of CI & DS & SE & $95 \%$ of CI \\
\hline Pooled & 195.31 & & $121.61-313.69$ & 45.438 & $30.585-67.505$ \\
\hline Alectoris chukar & 16.970 & 10.863 & $4.5504-63.285$ & 4.5438 & 2.1842 & $1.7897-11.536$ \\
\hline Tetraogallus himalayensis & 31.352 & 16.160 & $11.701-84.003$ & 9.0876 & 4.4029 & $3.5555-23.228$ \\
\hline Lepus oiostolus & 2.2719 & 1.5853 & $0.62479-8.2613$ & 2.2719 & 1.5853 & $0.62479-8.2613$ \\
\hline Marmota himalayana & 132.57 & 39.370 & $74.102-237.17$ & 21.583 & 5.2242 & $13.340-34.920$ \\
\hline Ochotona roylei & 7.2516 & 3.9322 & $2.5567-20.567$ & 4.5438 & 2.2485 & $1.7456-11.828$ \\
\hline Tetraogallus tibetanus & 4.8999 & 2.7973 & $1.6525-14.529$ & 3.4079 & 1.9431 & $1.1504-10.095$ \\
\hline
\end{tabular}

D - density of animals per $\mathrm{km}^{2}$, SE - standard error, CI - confidence interval, DS - density of cluster.

Most of the animals sighted from the line transect were either individuals or in very small groups.

\section{Results}

\subsection{Density of Wild Prey Species of Snow Leopard}

Blue sheep (Pseudois nayaur), musk deer (Moschus chrysogaster), Himalayan marmot (Marmota himalayana), Tibetan snowcock (Tetraogallus tibetanus), Himalayan snowcock (Tetraogallus himalayensis), hare (Lepus oiostolus), Royle's pika (Ochotona roylei) and chukar (Alectoris chukar) were the major wild prey species identified. The total combined prey species density estimate (except blue sheep) was 195.3 animals per $\mathrm{km}^{2}$ (Table 1). The effective strip width (ESW) of transect was $15.4 \mathrm{~m}$.

\subsection{Density and Population Size of Blue Sheep}

In all the three blocks covering a total area of $134.1 \mathrm{~km}^{2}$, a total of 304 blue sheep were sighted. The area had a density of 2.3 individuals per $\mathrm{km}^{2}$. The highest density of blue sheep was observed in Bhijer block with 2.7 animals per $\mathrm{km}^{2}$ and lowest in Samling block (1.9 animals/ km2). Twenty herds were observed and the heard size ranged from 2-49 animals per herd with an average of 15.2 animals per herd. The sex ratio constituted 67 males per 100 females. About 51 per cent of the animals observed were female.

\subsection{Livestock Status and Depredation}

All the households residing in Phoksundo, Bhijer and Saldang Village Development Committees own livestock.
Two hundred fifty households of these three villages owned 8,157 livestock. Saldang had the highest livestock holding per household with 49.1 animals, while Bhijer and Phoksundo had 32.1 and 17.4 animals per household, respectively. The highest livestock holding was 156 in Saldang and the least (only one animal) in Bhijer. About 20.8 per cent of the total households did not have yak (Bos grunniens grunniens) and only one household had more than 50 yak. Goat (Capra hircus)/ sheep (Ovis aries) were the majority forming 61.8 per cent of the total livestock. Fourty six per cent of the total household held small herds of 20 or fewer animal heads per household.

Each household lost 3.6 livestock annually. The total loss was 904 (11.1\%) of the total livestock population in a year. Goat/sheep were the most depredated animals of the park consisting $67.7 \%$ of the total depredation, whereas, horse consisted only $2.1 \%$ of the total depredation. The highest depredation of the livestock was observed in Bhijer VDC (19.2\%) and the lowest in Saldang (7.2\%).

\subsection{Cause of Livestock Depredation}

Snow leopards were the main cause of livestock loss; it predated $45.6 \%$ of the total livestock depredation. This was even higher in Bhijer where snow leopards caused $59.8 \%$ of the total livestock depredation. $22.0 \%$ of the total livestock died due to disease. It was followed by Tibetan wolf which resulted in $5.5 \%$ of the total livestock depredation. Though predators like brown bears and red fox have also been reported in Shey Phoksundo National Park, their predation on livestock was not reported in the study. This may be due to unawareness of the people of this area regarding their behaviors. Other reasons of depredation were starvation (12.4\%) and disaster (14.5\%) (Figure 3). 


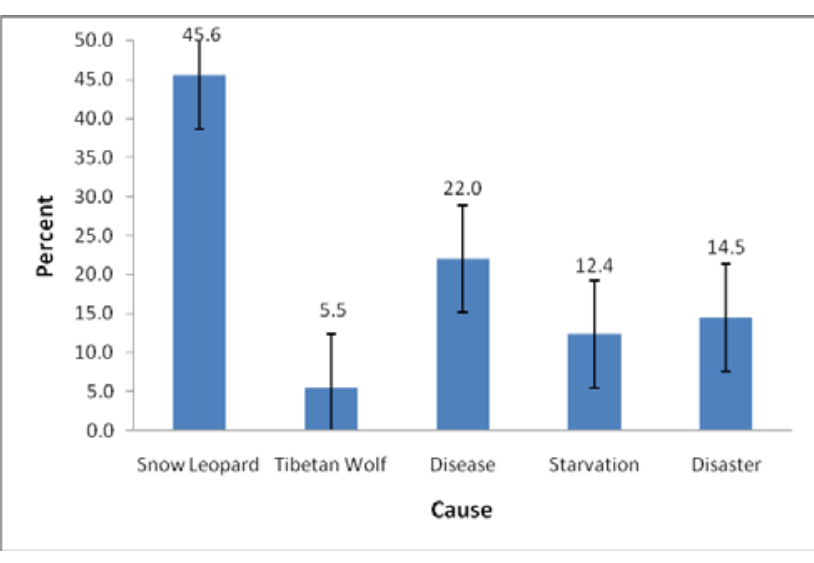

Figure 3. Per cent livestock depredation due to different factors

About $42.3 \%$ of the total depredation incidents occurred during the day time, $31.4 \%$ during night, $14.7 \%$ during evening and $11.7 \%$ during the morning. The highest depredation was observed during the winter season (39.8\%). There were marked differences in depredation during different seasons of the year with $30.2 \%$ during spring, $15.2 \%$ during summer and $14.8 \%$ during autumn.

\subsection{Diet Composition of Snow Leopard}

In the scats of snow leopard, three species of wild and four species of domestic mammals as well as birds were identified. Blue sheep dominated the diet of snow leopard, which consisted $30 \%$ of the identified prey items. Rodents were also the frequently consumed (17.5\%) next to blue sheep followed by the Himalayan marmot. Although, the species of birds present in the scat could not be identified, it was believed that they were Himalayan snowcock, Tibetan snowcock or chukar as these were the only large birds found in the area. Among the livestock, sheep were the main species found in the diet of snow leopard (15\%).

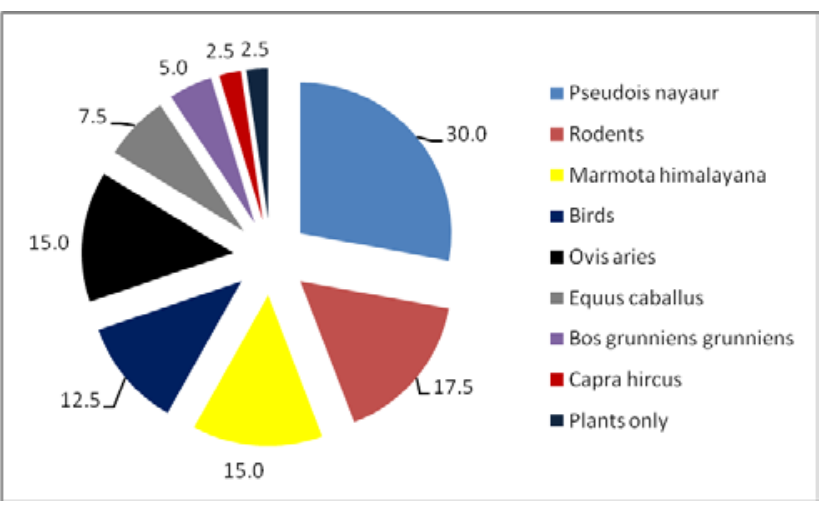

Figure 4. Frequency of occurrence of prey items in snow leopard diet

Most of the scats (87.5\%) contained only one prey species, while two prey types were contained in $12.5 \%$ of the scats (Figure 4). Plant materials such as grass, leaves and twigs were also found in the scat. One scat consisted only of plant materials, suggesting that snow leopards may eat plants deliberately.

Seventy per cent of the diet of snow leopards consisted of wild prey items of which 40 per cent consisted of blue sheep. Thirty per cent of the diet of snow leopards consisted of livestock items of which 53.8 per cent consisted of sheep.

\section{Discussion}

The species identified as prey of the snow leopard in this study are similar to those by Oli et al (1993) [18], who identified seven wild species as prey which also included blue sheep, Himalayan marmot, Royle pika in Annapurna Conservation Area, Nepal. Among the prey species identified, Himalayan marmot had the highest density. The marmot is considered a buffer prey species for snow leopards. It hibernates during the winter and comes out of hibernation in summer resulting in comparatively high density over the other prey species. Further, it can be sighted more easily and frequently compared to the other species, Chukars were sighted only in Bhijer and Samling, in areas having low altitude as compared to Shey block.

The blue sheep density of 2.3 per $\mathrm{km}^{2}$ compared to that reported in an independent study by Schaller (1977) [20] (8.8-10.0 per $\mathrm{km}^{2}$ ) is quite less. However, Schaller studied around Shey block which still shows slightly higher density (2.7 per $\mathrm{km}^{2}$ ) as compared to two other blocks in the present study. In 2008, Aryal [1] conducted similar study in Dhorpatan Hunting Reserve and found that the area had a density of 1.8 animals per $\mathrm{km}^{2}$. Compared to the study by Schaller (1977) [20], the density of blue sheep has decreased drastically over a period of three decades. Human disturbances and habitat destruction are the major causes of decline in the density of blue sheep in the area. The average herd size of 15.2 animals per herd is similar to the herd size of 15.6 animals per herd as reported by Oli (1991) [18] in Annapurna Conservation Area. Schaller (1977) [20] reported 18.4 animals per herd around the Shey area. With decrease in density of blue sheep in the area, the herd size has also decreased.

The livestock holding per household in Hemis National Park, India was 50.3 animals [2] and 26.6 animals in Annapurna Conservation Area [19]. The livestock holding per household in Shey Phoksundo National Park lies in between these two areas with an average of 32.6 animals per household. Livestock holding per household in Phoksundo VDC has decreased, whereas, the per household holding has increased in Bhijer and Saldang VDCs as compared to that in 2006. In 2006, livestock holding per household was 20.1, 31.0 and 37.9 in Phoksundo, Bhijer and Saldang VDCs, respectively[25]. In Phoksundo, people are attracted more towards tourism activities such as hotel, small shops, etc. Beside this, yak are the major livestocks reared in Phoksundo whereas goat/sheep are more commonly reared in Bhijer and Saldang.

In Annapurna Conservation Area, the overall depredation rate was 2.6 per cent [17]. In Hemis National Park, India, villagers lost 12 per cent of their livestock to predators in a fourteen months period [9]. The overall livestock depredation of this park is higher than that reported in other studies perhaps because it has higher densities of major predators like snow leopards and Tibetan wolves. The other possible reasons may be the remoteness of park and the livestock rearing system. In 2006, livestock loss per household in Saldang was 2.6 animals per household [25], which has increased to 3.5 animals/ household. This is also due to increase in livestock holding.

Loss to snow leopards averaged 1.6 animals per household and $5.1 \%$ of the total livestock holding. Oli et 
al. (1994) [19] reported 2.6\% of the livestock predated to snow leopards in Annapurna Conservation Area. This study shows higher livestock number depredated to snow leopards, which can be attributed to the high density of snow leopard in this park as compared to Annapurna Conservation Area. About 22.0\% of the livestock loss was due to diseases, which is the second cause of the loss in the Park. Actual rate of depredation of livestock in Shey Phoksundo National Park is not available. Though, this is important, but not easy to establish. People generally exaggerate their livestock having been predated to snow leopard, either deliberately, or due to inability to ascertain the causes of death. Further, livestock insurance schemes have been piloted in both Saldang and Bhijer VDCs, where the compensation for the snow leopard predated livestock is provided. This may be one of the reasons, why people claim their livestock is being predated by snow leopards so that they can obtain compensation even if the cause of death is different. Studies of predation problems in the United States have shown that livestock farmers tend to attribute death of their animals to predators regardless of the actual cause of death, and exaggerate the number of animals lost to predation [27]. In this study, use of local village leaders who were directly involved in verifying the cause of livestock death were involved and this should have minimized the errors in information obtained.

This seasonal variation in livestock depredation is similar to the study conducted by Oli et al. (1994) [19] in Manang of Annapurna Conservation Area, where, it was found that $42 \%$ of losses occured during winter, $28 \%$ in spring and $15 \%$ each in summer and autumn. Oli et al. (1994) [19] reported 39\% of the snow leopard scats collected during winter contained the remains of livestock, the analysis of faeces provided some support for the claim of high predation losses. During winter, sheep and goats grazed unattended and yak were left to roam free in the pastures, which increases greater chances of predation by wildlife. However, during the summer, shephards guard their livestock in the pastures. The highest depredation occurred during the day time, when livestock grazed in the open pastures where they share the habitat of wild animals, likely leading to depredation. Proper care during the herding time can reduce the depredation by wild animals. Finally, the topographic and steep terrain are the cause of accidental death of livestock.

Chundawat and Rawat (1994) [4] found that 25 scats contained only plant species (Myricaria germanica) which corroborate with the presnet study where one scat contained only plant species. This indicates that snow leopards may feed on plants delibaretly. Blue sheep was most frequently eaten prey in Shey and Lapche, Nepal, Taxkorgan reserve and Shule Nansham, China, whereas, ibex (Capra ibex) dominated the diet of Tamur Feng, China. Blue sheep were found in $50 \%$ and $70 \%$ of scats in Shey and Lapche, Nepal, respectively.Chundawat and Rawat (1994) [4] reported that domestic animals formed a significant part of snow leopard diets in Ladakh, with $10.2 \%$ of goat prey. Oli et al. (1994) [19] found yak in $13.6 \%$ of the scat in Annapurna Conservation Area, Manang, Nepal. In this study, sheep formed the major component of the snow leopard diet among the livestock, with 53.8 and 15.0 per cent of total livestock and overall diet, respectively.

\section{Conclusion}

The study focused on the diet of snow leopard in spring and shows that its diet is higher in wild prey species compared to livestock. Blue sheep dominated the diet of the snow leopard but small mammals like marmot and rodents and birds were also a major part of the food items. The diet of the snow leopad varies greatly in different parts of its range. There has been about 20 per cent decrease of blue sheep in the diet of snow leopard over a period of three decades when compared with the earlier studies in Shey and it can be attributed to the decrease in the density of blue sheep.

In Shey Phoksundo National Park, Himalayan marmots had the highest density among the wild prey species Among the domestic animals, goats/ sheep had the highest holding as well as the highest depredation rates. On analyzing the diet, it was, however, found that highest frequency in the diet was of blue sheep and sheep. This clearly indicates that the diet composition of snow leopards is independent of the density of wild prey species and that blue sheep is the most preferred species of snow leopard. The diet composition of snow leopard is not proportional to prey density. Thus, from this study we recommend that appropriate habitat should be maintained for the preferred prey of snow leopard for balancing the high altitude ecosystem. This study is, therefore, assumed to be very helpful for managers to create suitable environment for the survival of the endangered snow leopard and its prey species.

\section{Acknowledgements}

We are thankful to Snow Leopard Trust/Snow Leopard Conservancy/The Snow Leopard Network, USA for providing the research grant and IDEA WILD, USA for the research equipment grant to carry out this study. We also thank Department of National Parks and Wildlife Conservation, Shey Phoksundo National Park for the permission to carry out this research. We would like to acknowledge all the staff members of Park Headquarters and Rigmo Post for the logistic support. The generous support of the people of Phoksundo, Saldang and Bhijer is highly acknowledged.

\section{Abbreviations}

$\begin{array}{ll}\text { Hrs } & \text { Hours } \\ \mathrm{Km} & \text { Kilometer } \\ \mathrm{M} & \text { Meter } \\ \mathrm{Mm} & \text { Millimeter } \\ \mathrm{N} & \text { Numbers } \\ \text { VDC } & \text { Village Development Committee }\end{array}$

\section{References}

[1] Aryal, A., Population ecology and predators of blue sheep (Pseudois nayaur) in Dhorpatan Hunting Reserve, Nepal (M. Sc Thesis), Albert Ludwigs University of Freiburg, Germany. 56 p., 2008.

[2] Bhatnagar, Y.V., Wangchuk, R., and Jackson, R., A Survey of depredation and relatd wildlife-human conflicts in Hemis National 
Park, Ladakah, Jammu and Kashmir. International Snow Leopard Trust, Seattle, USA, 1999.

[3] Chaudhary, R., A bird checklist of Shey Phoksundo National Park, Department of National Parks and Wildlife Conservation, Shey Phoksundo National Park, Dolpa, Nepal, 2003.

[4] Chundawat, R. S. and Rawat, G. S., "Food habits of snow leopard in Ladakh, India” Proceedings of the Seventh International Snow Leopard Symposium, Fox, J. L. and D. Jizeng (eds.). International Snow Leopard Trust, Seattle, USA, pp. 127-132, 1994.

[5] DNPWC, Shey Phoksundo National Park and Buffer Zone Area Management Plan. Department of Nationa Park and Wildlife Conservation, Kathmandu, Nepal, 149 p., 2007.

[6] Fox, J. L., Sinha, S. P., Chundawat, R. S. and Das, P. K., “A field survey of snow leopard presence and habitat use in northwestern India" Proceedings of the Fifth International Snow Leopard Symposium, Freeman, H. (ed.), International Snow Leopard Trust and Wildlife Institute of India, pp. 99-111, 1988.

[7] Harris, R., "Wild ungulate surveys in grassland habitats: Satisfying methodological assumptions", Chinese Journal of Zoology 2 (31): 16-21, 1996.

[8] Jackson, R. and Hunter, D. O., Snow leopard survey and conservation hand book (Second ed.), International Snow Leopard Trust Seattle, Washington and U.S Geological Survey, Fort Collins Science Centre, Colorado, USA. 154p.+appendices, 1996.

[9] Jackson, R. M. and Wangchuk, R., “A community based approach to mitigating livestock depredation by snow leopards", Human Dimensions of Wildlife (9): 307-315, 2004.

[10] Jackson, R. M., Ahlborn, G. G., Gurung, M. and ALE, S., "Reducing livestock depredation losses in the Nepalese Himalaya", Proceedings of 17th Vertebrate Pest Conference, Timm, R.M. and A.C. Crabb (eds.). University of California, Davis, USA, p. 241247, 1996.

[11] Lovari, S., Boesi, R., Minder, N., Randi, E., Dematteis, A. and Ale, S. B., "Restoring a keystone predator may endanger a prey species in a human-altered ecosystem: the return of the snow leopard to Sagarmatha National Park”, Animal Conservation (12): 559-570, 2009.

[12] Maheshwari, A., Food habits and prey abundance of leopard (Panthera pardus fusca) in Gir National Park and Wildlife Sanctuary (M.Sc Thesis), Aligarh Muslim University, Aligarh, India. 64 p., 2006.

[13] Mallon, D., “The snow leopard in Ladakh”, International pedigree book of snow leopards. Vol. 4. Blomqvist, L. (ed.). Helsinki, Finland, p. 23-37, 1984.

[14] Mukherjee, S., Goyal, S. P. and Chellam, R., "Standardisation of scat analysis techniques for leopard (Panthera pardus) in Gir National Park, Western India”, Mammalia, 139-143, 1994.
[15] Nowel, K. and Jackson, P., "Wild cats: Status survey and conservation action plan” IUCN/SSC Cat Specialist Group, IUCN, Gland, Switzerland: 382 p., 1996.

[16] Oli, M. K., "Seasonal patterns in habitat use of blue sheep Pseudois nayaur (Artiodactyla, Bovidae) in Nepal”, Mammalia 60 ( 2): 187-194, 1996.

[17] Oli, M. K., The ecology and conservation of snow leopard (Panthera uncia) in the Annapurna Conservation Area, Nepal (M. Phil. Thesis), University of Edinhurgh, UK. 155 p., 1991.

[18] Oli, M. K., Taylor, I. R. and Rogers, M. E., "Diet of snow leopard (Panthera uncia) in the Annapurna Conservation Area, Nepal", Journal of Zoology 231: 365-370, 1993.

[19] Oli, M. K., Taylor, I. R. and Rogers, M. E., "Snow leopard Panthera uncia predation of livestock: An assessment of local perceptions in the Annapurna Conservation Area, Nepal”, Biological Conservation 68(1): 63-68, 1994.

[20] Schaller, G., Mountain monarchs: wild sheep and goats of the Himalaya, University of Chicago Press, Chicago, USA. 425 p., 1977.

[21] Schaller, G., Wildlife of the Tibetan steppe, University of Chicago Press, Chicago, USA, 1998.

[22] Schaller, J. B., Hong, T. L., Junrang, R., Mingjiang, Q. and Haibin, W., "Status of large mammals in Taxkorgan Reserve", Biological Conservation (42): 53-71, 1987.

[23] Sharma, S., Thapa, K., Chalise, M. K, Dutta, T., Bhatnagar, Y. V. and Mccarthy, T. M., "The snow leopard in Himalaya: A step towards their conservation by studying their distribution, marking habitat selection, coexistence with other predators, and wild preylivestock-predator interaction”, Conservation Biology in Asia, 184-196, 2006.

[24] Teering, B., Hair of Western-European mammals: atlas and identification key, Cambridge University Press, New York, USA. 224 p., 1991.

[25] Thapa, K., Study on status and distribution of the snow leopard and blue sheep including people interactions, Kanchanjungha Conservation Area and Shey Phoksundo National Park. WWF Nepal, Kathmandu, Nepal. 34 p., 2006.

[26] Thomas, L., Laake, J. L., Rexstad, E., Strindberg, S., Maques, F. F C., Buckland, S. T., Borchers, D. L., Anderson, D. R., Burnham, K. P., Burt, M. L., Hedley, S. L., Pollard, J. H., Bishop, J. R. B. and Marques, T. A., Distance 6.0. release 2, Research unit for wildlife population assessment, University of St. Andrews, UK, 2009. http://www.ruwpa.st-and.ac.uk/distance/.

[27] Wanger, F., Predator control and the sheep industry: the role of science in policy formation, Regina Books, Claremont, California, USA, 1988 